\title{
El Mundo Hispano Sin Fronteras: uma proposta de curso Mooc Gamificado
}

\author{
Guilmer Brito Silva ${ }^{1}$ \\ Luís Paulo Leopoldo Mercado \\ Delia Hilda Ortiz ${ }^{3}$
}

Programa de Pós-Graduação em Educação, Universidade Federal de Alagoas, Maceió, AL, Brasil

Resumo: O Massive Open Online Course (MOOC) se apresenta como uma ferramenta valiosa na educação não formal, nas áreas de formação continuada e educação aberta, contribuindo para a democratização e disseminação de conhecimentos e favorecendo a aprendizagem. A construção de $\mathrm{MOOC}$ utilizando a gamificação por meio de um ambiente desafiador e motivante favorece ao maior engajamento dos participantes, colaborando com uma maior interação dos alunos com os materiais didáticos e atividades do curso. Este artigo relata a elaboração de cursos online abertos e massivos, utilizando a gamificação. Para isso, foi realizado um levantamento epistemológico sobre a temática dos MOOCs e da gamificação. Foi construído e ofertado um curso SPOC experimental sobre o ensino de língua estrangeira (espanhol) no ambiente virtual de aprendizagem (AVA) Moodle, visando a validação da proposta. Após a realização do curso e análise dos dados do mesmo, concluiu-se que as aplicabilidades e potencialidades da gamificação são importantes para melhorar algumas fragilidades e especificidades de cursos MOOCs.

Palavras-chave: MOOC; Gamificação; Design pedagógico.

Title: El Mundo Hispano Sin Fronteras: aproposal of the Mooc Course

Abstract: The Massive Open Online Course (MOOC) is a valuable tool in non-formal education, in theareasofcontinuingeducationand open education, contributing to the democratization and dissemination of knowledge and favoring learning. The construction of MOOC using gamification through a challenging and motivating environment favors greater participant engagement, contributing to greater student interaction withthe course materials and activities. This article reports the design of MOOC using gamification. For this, na epistemological survey was conducted on the theme of MOOCs and gamification. An experimental SPOC course on foreign language teaching (Spanish) was built and offered to validate the proposal. After the course and data analysis, it was concluded that the applicability and potentialities of gamification are important to improve some weaknesses and specificities of MOOCs courses.

Keywords: MOOC; Gamification; Pedagogical design.

\footnotetext{
${ }^{1}$ Doutor (Universidade Federal de Alagoas), UFAL. Orcid: https://orcid.org/0000-0002-6131-3671

E-mail: guilmerbs@gmail.com

${ }^{2}$ Doutor (Pontifícia Universidade Católica de São Paulo), UFAL. Orcid: https://orcid.org/0000-0001-8491-6152

E-mail: luispaulomercado@gmail.com

${ }^{3}$ Mestre (Universidade Interamericana- República do Paraguai), SENAC. Orcid: https://orcid.org/0000-00032712-222X

E-mail: delia.ortiz@al.senac.br
} 


\section{Introdução}

No cenário contemporâneo da cibercultura, condicionado pela evolução das tecnologias digitais da informação e comunicação (TDIC), em especial as ligadas à internet e das tecnologias móveis, surge uma mudança de paradigma educacional. Essa nova realidade tem alterado a maneira como as pessoas se comportam em relação às diversas áreas do conhecimento. Então, emerge a necessidade de adoção de novos recursos e estratégias didáticas para a criação de novas práticas pedagógicas (BACICH; MORAN, 2018), nas quais se destacam as modalidades de ensino blended learning ou ensino híbrido (BACICH, TANZI NETO; TREVISANI, 2015; HORN; STAKER, 2015) e flipped classroom ou sala de aula invertida (VALENTE, 2014; BERGMANN; SAMS, 2016; TALBERT, 2019), envolvendo o uso de recursos MOOC, plataformas adaptativas, aplicativos de mobile learning e estratégias de ensino como a gamificação.

No campo da Educação, há interesses e necessidades crescentes de abordagens pedagógicas que contemplem experiências cognitivas dos alunos, a partir de recursos e materiais didáticos multimidiáticos, ambientes imersivos, criação de cenários (espaços) de aprendizagem interativos, motivantes e colaborativos. Tudo isso para proporcionar novas experiências pedagógicas. Dentre essas novas propostas metodológicas, os cursos online abertos e massivos, do inglês Massive Open Online Courses (MOOCs) e a gamificação têm conseguido visibilidade.

Os cursos MOOCs podem ser vistos como uma estratégia contemporânea relevante. Com o aumento exponencial de informações na internet, os MOOCs podem ser uma fonte de conhecimento. Já o uso da gamificação no contexto educacional, seja presencial, a distância, seja híbrida, tem como objetivo fazer com que o ensino se torne mais atrativo aos alunos (MUNTEAN, 2011).

O foco deste estudo visa à contextualização de cursos ofertados no formato MOOC, a fim de aprofundar as pesquisas sobre como planejar, organizar e elaborar MOOC, utilizando a gamificação, aumentando assim o engajamento dos participantes. Segundo Bates (2016), os MOOCs são uma ferramenta original e valiosa para a educação continuada e informal e precisam ser julgados dentro desse contexto. É nessa visão que este estudo se desenvolve e defende a aplicação e potencialidades dos MOOCs.

Foi elaborada e realizada uma oferta de curso experimental, usando a gamificação, para validação da proposta de design pedagógico. Para esse protótipo foi ofertado um curso Small Private Online Course (SPOC), que segundo Mattar (2013), são pequenos cursos online privados, destinados a grupos menores, o que propõem ser uma experiência mais personalizada. A partir da análise desse curso SPOC poderemos estabelecer elementos e características que servirão de base para futuros $\mathrm{MOOC}$ gamificados. O conteúdo do curso foi 
sobre o ensino de uma língua estrangeira (espanhol). A elaboração do SPOC na área de língua estrangeira baseou-se em um curso de extensão já ofertado na Universidade Federal de Alagoas (UFAL), com materiais didáticos produzidos, revisados e validados. Para montagem do curso, utilizamos o Moodle como estrutura base, assim sendo, o curso gamificado funcionou dentro da plataforma Moodle. A escolha do AVA Moodle ocorreu por suas características de software de código aberto e livre utilização.

Após a realização do curso, concluiu-se que o uso de MOOCs gamificados podem motivar o aluno no ambiente do curso e promover uma maior interação do aluno com os materiais didáticos e atividades.

\section{MOOC como alternativa às demandas da Cultura Digital}

No Brasil, já existem centenas de iniciativas baseadas nos MOOCs, até com cursos de universidades internacionais traduzidos para o português, além de experiências de universidades nacionais como a Universidade de São Paulo (USP), a Universidade Estadual Paulista (Unesp), a Universidade Federal de Minas Gerais (UFMG) e a Universidade Estadual de Campinas (Unicamp). Recentemente, em 2018, a Universidade Federal de São Carlos (UFSCar) lançou o PoCA, portal de cursos MOOCs, destinado à comunidade acadêmica e ao público em geral, com certificação também gratuita e a UFRGS lançou a plataforma de cursos Lúmina.

Segundo Matta e Figueiredo (2013), os MOOCs são cursos online organizados em ambiente digital com conteúdo em diversas mídias e compartilhados para quem se interessar. Por essa característica de conteúdos específicos organizados e disponibilizados para quem tem interesse, muitos usuários exploram os recursos não em busca de certificados, mas principalmente em busca de informação confiável. O MOOC oferece aprendizado em partes, no próprio ritmo do aluno.

As principais características dos MOOCs são: ser aberto, normalmente gratuitos (alguns exigem pagamento apenas para certificação), colaborativo, distribuído, com compartilhamento de informação e conteúdo de forma rápida e com um grande número de sujeitos envolvidos (YUAN et al., 2012).

Méndez García (2013) ressalta que MOOC não deve ser pensado simplesmente como um AVA em larga escala, que possibilita difundir o conhecimento ao maior número possível de alunos, mas também como um ambiente gratuito, onde pessoas que não podem pagar ou ter acesso a instituições educacionais possam seguir com a sua formação, sem ser da forma tradicional. 
Perna e Ruby (2013) revelam que muitos se inscrevem nos cursos, mas apenas poucos se tornam participantes ativos, em que o nível de engajamento dos participantes costuma cair dramaticamente após 1 a 2 semanas do curso. Em média $4 \%$ dos alunos inscritos alcançaram nota final acima de $80 \%$, demonstrando que apenas poucos persistem até o final das atividades propostas pelo curso.

Selingo (2014) argumenta que, usando as métricas pelas quais julgamos o ensino superior tradicional, os MOOCs falharam em cumprir sua promessa original. Mas essas métricas não levam em conta como os MOOCs estão sendo usados atualmente e o perfil dos estudantes que procuram esse tipo de curso. Primeiramente, os alunos podem se inscrever gratuitamente, para quantos cursos quiserem. Alguns podem querer experimentar por curiosidade, ou buscam informações específicas para uma aula ou uma apresentação, ou querem aprofundar conhecimentos sobre um ponto particular. Esses alunos não planejaram concluir o curso e não têm nada a perder quando deixam de fazer o curso.

Já os SPOCs, surgem como uma variação dos cursos MOOC e são um modelo adotado para cursos menores e pontuais. Segundo Lin (2016), os cursos SPOC se caracterizam por ser de pequena escala e dentro de um determinado intervalo de tempo, tornando-o mais controlável, pois elementos como progresso do aluno na aprendizagem, motivação, tópicos de comunicação e atividades são melhor acompanhados pelo professor. Ainda segundo a autora, a maior vantagem dos cursos SPOC é proporcionar aos alunos uma melhor experiência, onde os alunos podem participar de forma mais efetiva e direcionada da sua aprendizagem. Os professores podem, neste modelo, melhor identificar e melhorar os percursos de aprendizagem da turma, pois as necessidades dos alunos podem ser melhor identificadas e ajustadas no processo de aprendizagem.

Para Grover et al. (2013), os MOOCs estão em plena transformação e seus formatos e funções têm evoluído continuamente pela ação de especialistas em design pedagógico e pelas próprias plataformas provedoras, tornando o estudo de $\mathrm{MOOC}$ bastante desafiador em vários sentidos.

\section{Gamificação: conceito e possibilidades educacionais}

Deterding et. al (2011), Vianna et al (2013) e Fadel et al (2014) afirmam que a gamificação é um fenômeno emergente que surge da popularidade dos jogos digitais e de sua capacidade de motivar ações, resolver problemas, potencializar aprendizagens em diversas áreas do conhecimento. Consiste em se apropriar dos elementos dos jogos aplicados em contextos, produtos e serviços necessariamente não focados em jogos. Ou seja, gamificar uma atividade não significa criar um jogo. Envolve mecanismos e dinâmicas de jogos para a resolução de problemas e para a motivação e engajamento de um determinado público. A gamificação não é um jogo ou processo para se transformar algo em jogo, mas sim a utilização 
de abstrações e metáforas originárias dos games em áreas não relacionadas a games.

Pimentel (2018) destaca que a gamificação tem seu surgimento no âmbito coorporativo e tem ganhado espaço no contexto educacional, mas que ela, com fins pedagógicos, implica uma proposta que vai um pouco além da implementação e uso dos games em atividades educacionais. Segundo o autor, a gamificação deve ir além do engajamento e da motivação, como também da intenção de que a aprendizagem seja "divertida".

Ao buscar conceituar a gamificação no contexto educacional, o autor define que a gamificação é o processo de utilização da mecânica, estilo e do pensamento de games, em contexto não game, como meio para engajar e motivar pessoas, objetivando a aprendizagem por meio da interação entre pessoas, com as tecnologias e com o meio (PIMENTEL, 2018).

Mcgonigal (2011) afirma que por meio da gamificação é possível: engajar, sociabilizar, motivar e ensinar de maneira mais eficiente. A gamificação é uma técnica que faz uso de jogos em situações que não visam ao puro entretenimento, estimulando a criatividade, o pensamento crítico, o engajamento, a motivação, o trabalho em equipe e a independência na resolução de problemas (KAPP et al., 2014).

Schlemmer (2014) destaca que, para não cairmos em modismos - utilizando apenas elementos como ranqueamento, pontuação, classificação, etc., no desenvolvimento da gamificação em contextos educacionais, devemos priorizar o uso de elementos dos games que possam levar a um maior engajamento e motivação em atividades pedagógicas. Ainda segundo a autora, a gamificação pode ser pensada por meio de duas perspectivas: a persuasão, que reforça uma perspectiva epistemológica empirista, por sistemas de pontuação, recompensas, entre outros; e a construção colaborativa e cooperativa, sendo desenvolvida por meio de desafios, missões, descobertas, empoderamento em grupo, numa perspectiva epistemológica interacionista-construtivista-sistêmica (SCHLEMMER, 2014).

Segundo Mattar (2010), a gamificação encontra na Educação uma área bastante fértil para a sua aplicação. Além disso, nessa área há a necessidade de novas estratégias para dar conta de indivíduos que cada vez estão mais inseridos no contexto da cibercultura, conectados às mídias e às TDIC, os quais se mostram desinteressados pelos métodos de ensino e aprendizagem tradicionais e passivos.

Para entender melhor como a gamificação pode efetivamente ser utilizada para aumentar a motivação e o desempenho dos alunos em sala de aula, Stott e Neustaedter (2013) apresentam em seu estudo que o uso da gamificação pode auxiliar o processo de ensino e aprendizagem. Os autores citam que, ao se utilizar a gamificação, os professores podem direcionar seu ambiente de sala de aula para aumentar o engajamento dos alunos. Contudo, os autores ressalvam que, como acontece com qualquer referencial pedagógico, um educador deve ter cuidado para considerar o contexto de ensino ao qual estão engajados, quem são os seus alunos e quais são os objetivos a serem atingidos. 
A proposta de SPOC gamificado elaborada, foi fundamentada nos elementos de Werbach e Hunter (2012) que estruturam a gamificação em três camadas: dinâmica, mecânica e componentes. Zichermann e Cunningham (2011) e Kapp (2012) destacam que a estrutura MDA é a mais utilizada. Para o desenvolvimento desta pesquisa, optamos por usar o modelo MDA, por ser a estrutura mais referenciada para gamificar conteúdos pedagógicos.

\section{SPOC Gamificado: El Mundo Hispánico Sin Fronteras}

Para montagem do SPOC gamificado, foi selecionado o Curso de Extensão Universitária intitulado "El Mundo Hispánico Sin Fronteras" (Figura 1), promovido pela Coordenadoria Institucional de Educação a Distância (Cied) da Ufal, com a colaboração da Universidade Aberta do Brasil (UAB).

Figura 1 - Banner de divulgação do curso

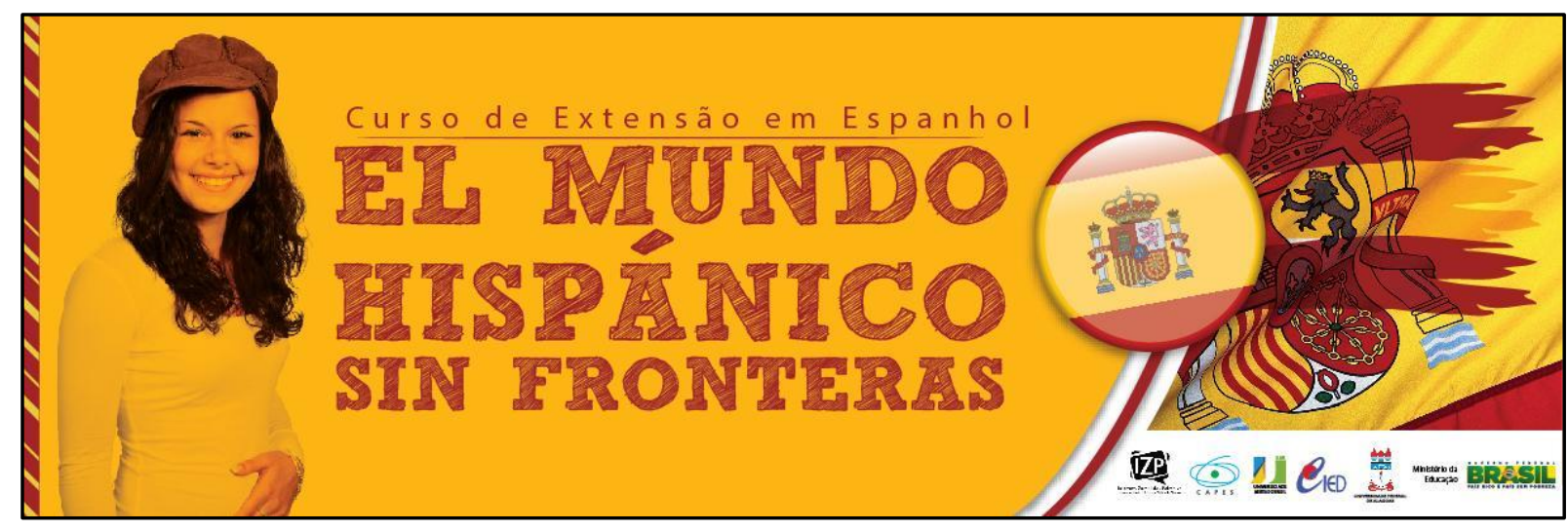

Fonte: site https://ava.ead.ufal.br

O curso está estruturado em três módulos com duas unidades cada módulo, perfazendo um total de seis unidades. Apresentam os conteúdos do nível A1, definidos nos níveis de referência para o espanhol, e segue as recomendações do Marco Comum Europeu de referência para as línguas: aprendizagem, ensino, avaliação. Cada unidade é dividida em cinco Contenidos, sendo eles: Funcionales, Lexicales, Gramaticales, Culturales e Síntesis Contrastiva (Figura 2). 
Figura 2 - Ambiente do curso

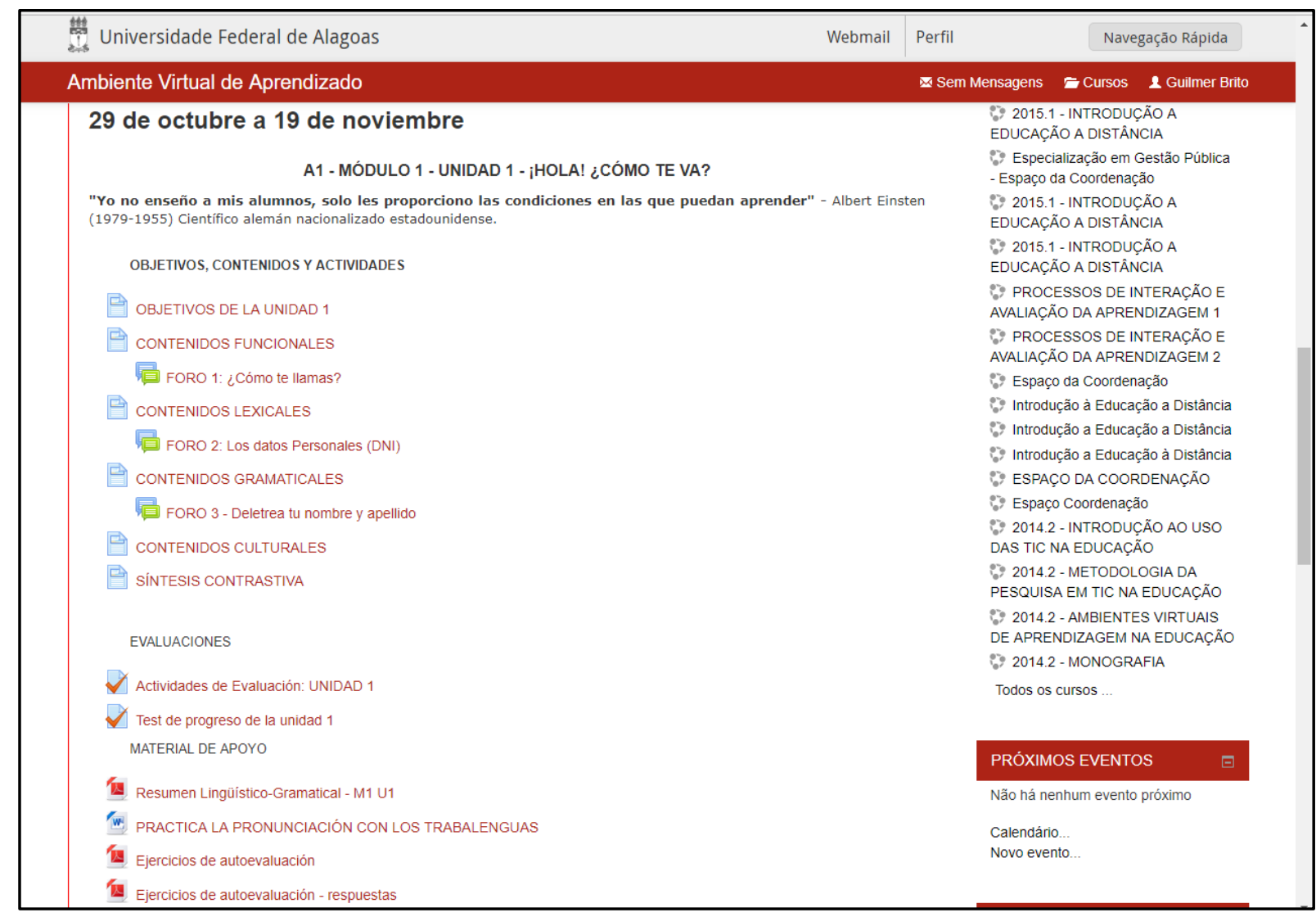

Fonte: site https://ava.ead.ufal.br

Todas as unidades utilizaram videoaulas; cada unidade possui seu fórum e respectiva avaliação; a distribuição do conteúdo em módulos, unidades e conteúdos tiveram por objetivo proporcionar uma evolução progressiva de conhecimento dos alunos, explorando os diálogos por meio de videoaulas e do uso de quizzes autoavaliativos. O curso foi programado para ocorrer no período de seis meses.

Para o desenvolvimento do curso, foram elaborados os seguintes materiais didáticos: material impresso; materiais audiovisuais, tais como: vídeos, animações e áudios. Por todas essas características, o curso mostra-se adaptável para a transposição do seu conteúdo para uma perspectiva de um MOOC. A professora autora do curso e a Ufal autorizaram a utilização desse conteúdo, para fins de estudo nessa pesquisa.

Para a elaboração do SPOC gamificado, foi composta uma equipe com os seguintes profissionais: um ilustrador, um programador (desenvolvedor) e um designer, além do pesquisador que atuou como projetista e designer de games.

Dando início ao processo de gamificação do Curso de Espanhol, foram realizadas algumas reuniões com a equipe para conhecer o curso a ser gamificado, sua estrutura, seu conteúdo, seus objetivos, público-alvo, materiais didáticos, atividades, entre outros 
elementos. Para desenvolver a narrativa, utilizou-se da proposta de Histórias em quadrinhos (HQ) para contar as aventuras do personagem. A estrutura de $\mathrm{HQ}$, além de possibilitar uma maior integração do conteúdo com o aluno, também contribui para a criação de um ambiente de imersão do aluno com os materiais didáticos e atividades do curso. Explora também a curiosidade, além do envolvimento com o próprio conteúdo da história, que gera interesse em acompanhar os desfechos das aventuras do personagem. Todo o material elaborado para a proposta de gamificação do curso é autoral (Figura 3), tais como: o enredo, os personagens, a mecânica e a dinâmica.

Figura 3 - Tela inicial do curso SPOC de espanhol

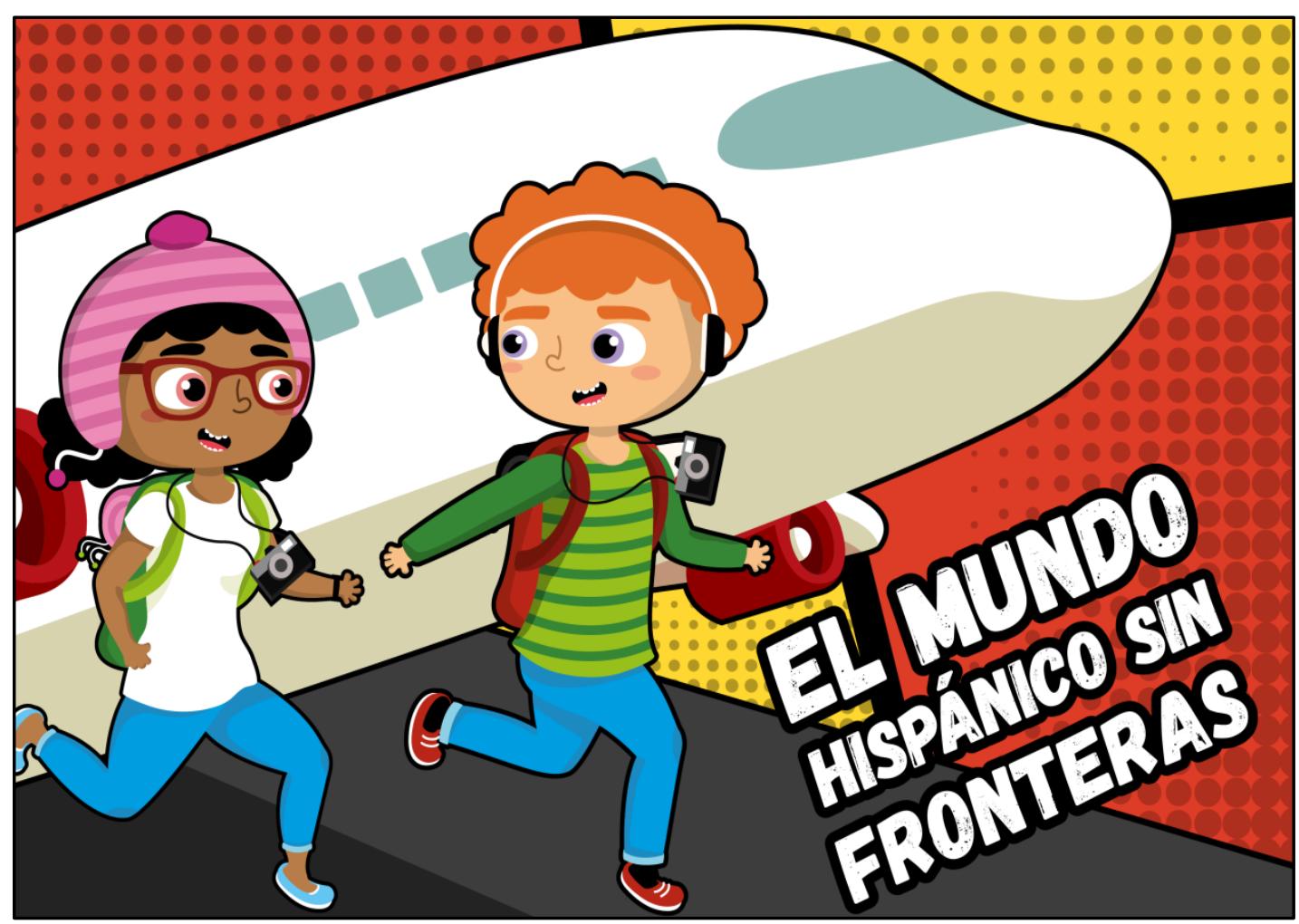

Fonte: Autoral. Elaborado pela equipe de desenvolvimento.

Toda a narrativa foi pensada para contextualizar os conteúdos didáticos do curso dentro de um enredo com uma lógica contínua de ações e eventos. Por exemplo, temos o Contenidos Funcionales do módulo 2 - unidade 4, que é sobre vestimentas, então nesse momento o personagem estará em uma loja de roupas no aeroporto (Figura 4) realizando alguma ação. Em outro momento, há um conteúdo didático sobre objetos de uma escola, Contenidos Lexicales do módulo 1 - unidade 2, então o personagem estará conversando com um professor no aeroporto (Figura 5), onde o diálogo abordará o assunto. 
Figura 4 - HQ do personagem um uma loja de roupa

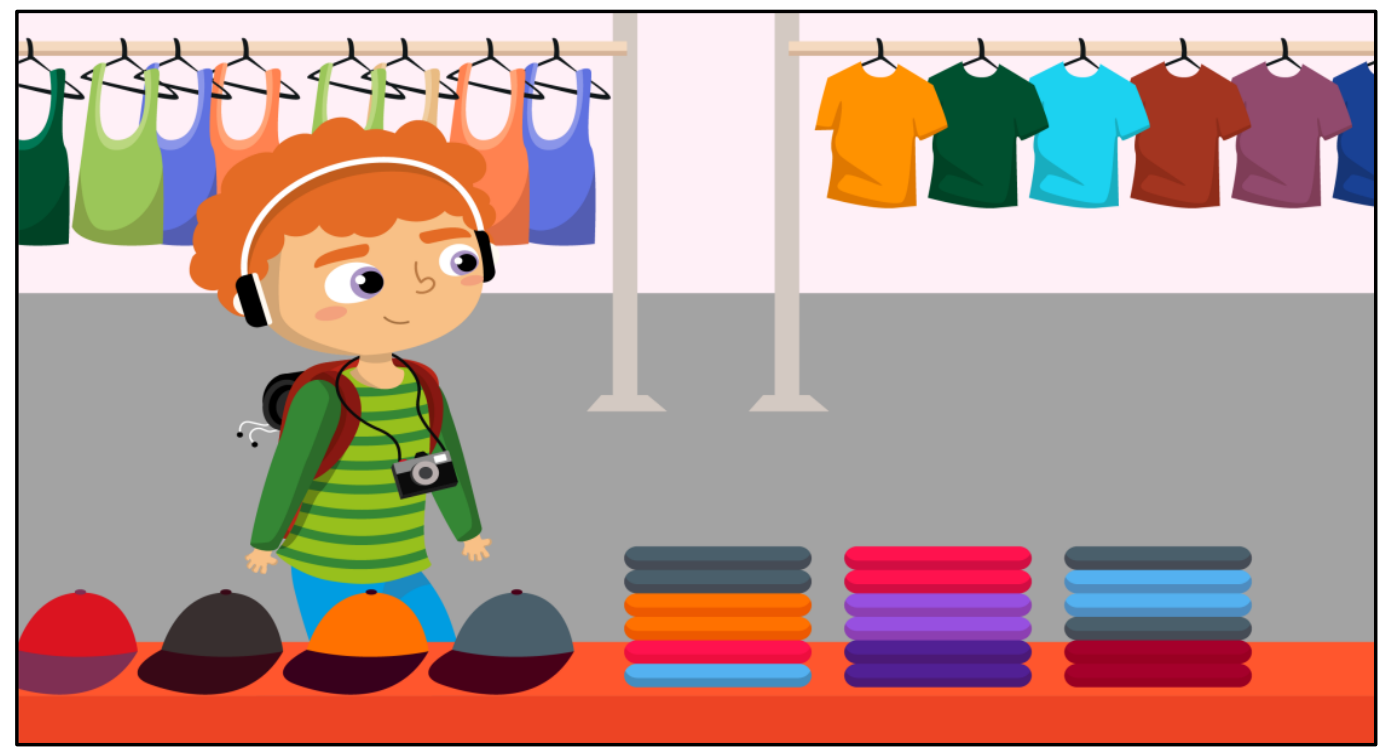

Fonte: Autoral. Elaborado pela equipe de desenvolvimento.

Figura 5 - HQ do personagem conversando no aeroporto

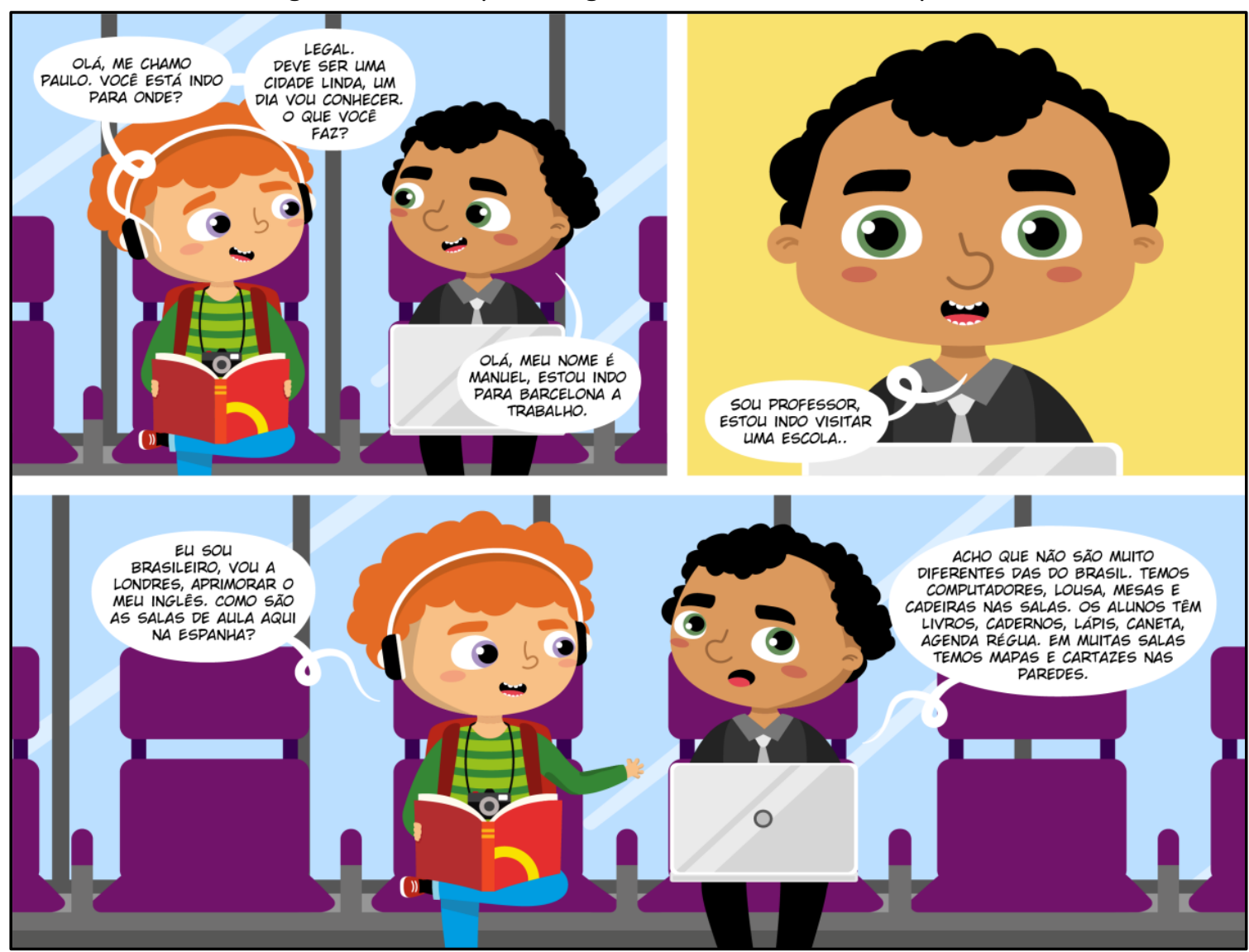

Fonte: Autoral. Elaborado pela equipe de desenvolvimento.

No Quadro 1, descrevemos como foi elaborado um enredo que estivesse relacionado 
aos conteúdos de cada unidade do curso e que mantivesse um sentido lógico para as ações que ocorriam com o personagem ao longo da história (curso).

\section{Quadro 1 - Relação do conteúdo do curso com o enredo elaborado}

(continua)

\begin{tabular}{|c|c|}
\hline \multicolumn{2}{|c|}{$\begin{array}{l}\text { Início do MOOC gamificado: Universitário (a) fazendo primeira viagem ao exterior, indo para } \\
\text { Londres. Ele (a) faz uma escala em Madri e acaba perdendo o voo, porque se distrai e } \\
\text { confunde o portão de embarque, dando início a sua aventura. }\end{array}$} \\
\hline \multicolumn{2}{|c|}{ Módulo 1 / Unidad 1: ihola! ¿cómo te va? } \\
\hline Conteúdos & Enredo \\
\hline $\begin{array}{l}\text { Saludos y despedidas } \\
\text { Los datospersonales } \\
\text { Las nacionalidades } \\
\text { Laspresentaciones }\end{array}$ & $\begin{array}{l}\text { Personagem conversando com um } \\
\text { funcionário do aeroporto, que indica o } \\
\text { próximo ponto que o personagem deve ir. A } \\
\text { central de atendimento no aeroporto. } \\
\text { Personagem se apresentar ao funcionário na } \\
\text { central de atendimento, fornecendo seus } \\
\text { dados pessoais. A funcionária informa que } \\
\text { ele terá que ficar } 24 \mathrm{~h} \text { no aeroporto, para } \\
\text { esperar o próximo voo, que será às } 8 \mathrm{~h} \text { do } \\
\text { outro dia. }\end{array}$ \\
\hline
\end{tabular}

Módulo 1 / Unidad 2: ihola! ¿a qué te dedicas?

\begin{tabular}{|l|l|}
\hline Conteúdos & Enredo \\
\hline $\begin{array}{l}\text { ¿a qué te dedicas? } \\
\text { Enel aula }\end{array}$ & $\begin{array}{l}\text { Personagem na sala de embarque lendo ao } \\
\text { lado de uma pessoa. O personagem inicia }\end{array}$ \\
Los profesionales y los ofícios & $\begin{array}{l}\text { uma conversa. O outro personagem é um } \\
\text { professor que está indo ministrar uma } \\
\text { palestra. Eles conversam sobre as salas de } \\
\text { aula na Espanha. }\end{array}$ \\
\hline
\end{tabular}

Módulo 2 / Unidad 3: esta es mi família

\begin{tabular}{l|l} 
Conteúdos & Enredo
\end{tabular}

La familia: descripción y entorno

O personagem sente fome e vai para um

El aspecto físico

La personalidade restaurante e encontra uma pessoa (um pai de família). Se inicia um diálogo. O pai apresenta sua família e fala das características de todos.

Módulo 2 / Unidad 4 - somos diferentes y somos lo que llevamos

\begin{tabular}{|l|l|}
\hline Conteúdos & Enredo \\
\hline La vestimenta & Personagem anda pelo aeroporto e fala com \\
El cuerpo & um segurança sobre a localização de uma \\
\hline
\end{tabular}




\begin{tabular}{|c|c|}
\hline Los colores & $\begin{array}{l}\text { loja de roupas. Personagem na loja de } \\
\text { roupas, olhando diversas peças, tamanhos e } \\
\text { cores. }\end{array}$ \\
\hline \multicolumn{2}{|c|}{ Módulo 3 / Unidad 5 - nuestra rutina ¿̇a qué hora te levantas? } \\
\hline Conteúdos & Enredo \\
\hline $\begin{array}{l}\text { La rutina } \\
\text { La hora } \\
\text { Los meses delaño } \\
\text { Las estaciones delaño }\end{array}$ & $\begin{array}{l}\text { Personagem vai a uma cafeteria e conhece } \\
\text { uma pessoa. Começa uma conversa e vai } \\
\text { descobrir sobre a rotina dela. Personagem se } \\
\text { informa sobre quanto tempo falta para } \\
\text { pegar o voo, com a atendente da cafeteria. }\end{array}$ \\
\hline \multicolumn{2}{|l|}{ Módulo 3 / Unidad 6 ¿dónde vives? } \\
\hline Conteúdos & Enredo \\
\hline $\begin{array}{l}\text { La ciudad } \\
\text { Pedir y dar informaciónenlaciudad } \\
\text { Lastiendas: ¿a dóndevas para...? } \\
\text { Los medios de transporte } \\
\text { La casa: ¿dónde se puedevivir? } \\
\text { La casa: vocabulário }\end{array}$ & $\begin{array}{l}\text { Personagem lendo o livro sobre Madri, o } \\
\text { qual comprou na livraria do aeroporto. Após } \\
\text { isso, o personagem vai jantar e conhece } \\
\text { outra pessoa e conversam. }\end{array}$ \\
\hline
\end{tabular}

Fonte: Elaboração dos autores (2019).

Descreveremos a seguir toda a dinâmica, mecânica e comportamentos do curso MOOC gamificado que foi desenvolvido.

\section{Dinâmica}

Narrativa: um(a) jovem universitário(a), fazendo primeira viagem ao exterior, indo para Londres fazer um curso de imersão em inglês. Ele(a) faz uma escala na cidade de Madrid/Espanha e acaba perdendo o voo para Londres, porque confunde o portão de embarque, dando início a sua aventura. Foram elaborados personagens do sexo feminino e masculino para esse enredo (Figura 6). 
Figura 6 - Personagens desenvolvidos para o curso

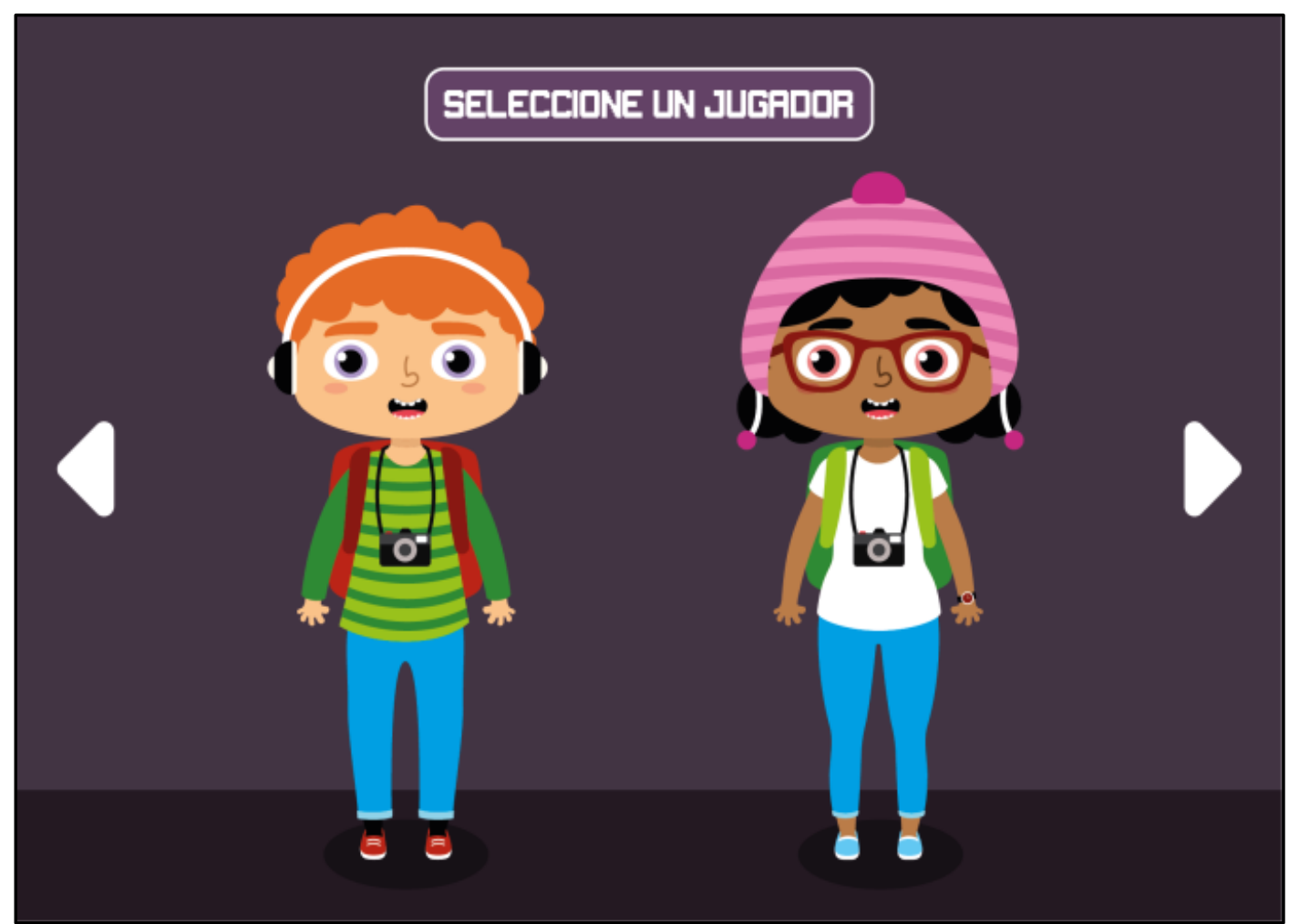

Fonte: Autoral. Elaborado pela equipe de desenvolvimento.

Do ponto de vista da gamificação, Schmitz, Klemke e Specht (2012) entendem que no contexto de aprendizagem agentes como personagens têm efeito direto no envolvimento do aluno. A partir da escolha do personagem, a história se desenvolve na perspectiva do mesmo, então, a depender da escolha do aluno, as HQs irão mudar (Figuras 7 e 8).

Figura 7 - HQ na perspectiva do personagem feminino

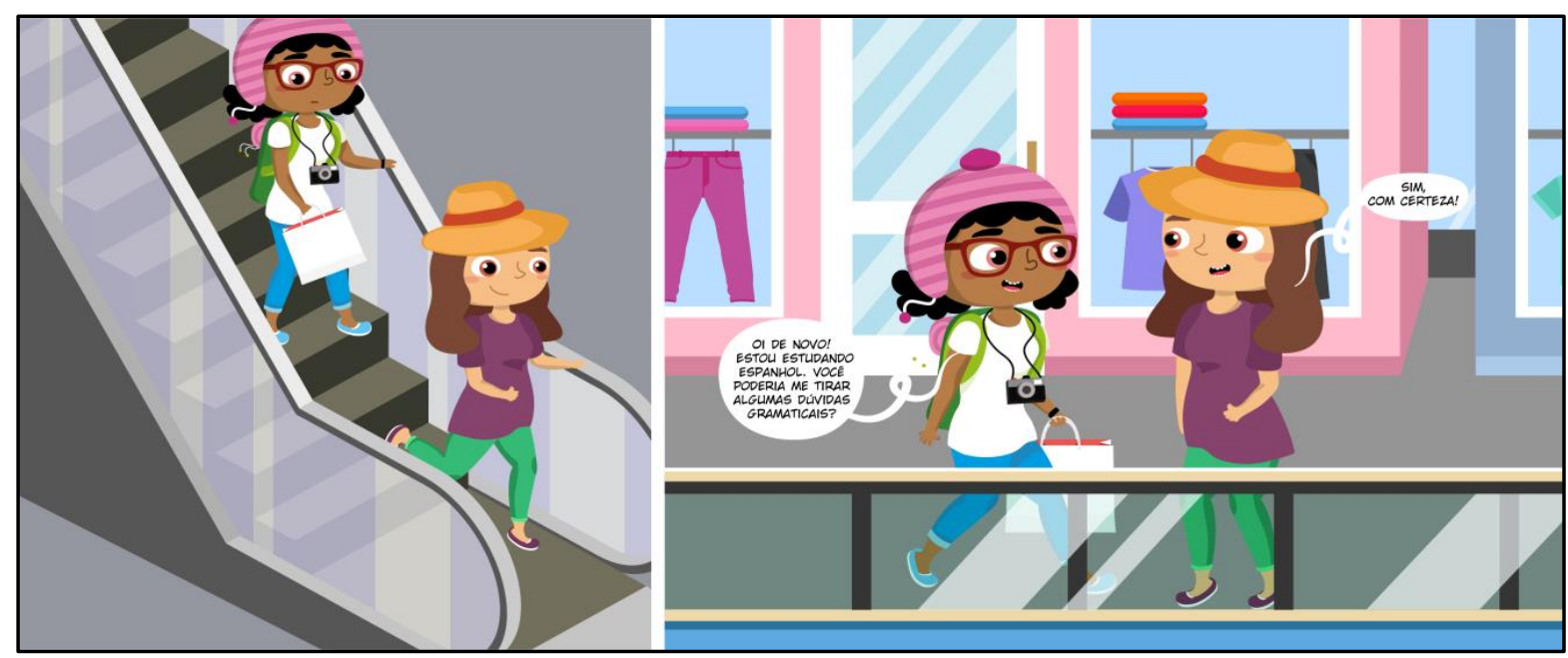

Fonte: Autoral. Elaborado pela equipe de desenvolvimento. 
Figura 8 - HQ na perspectiva do personagem masculino

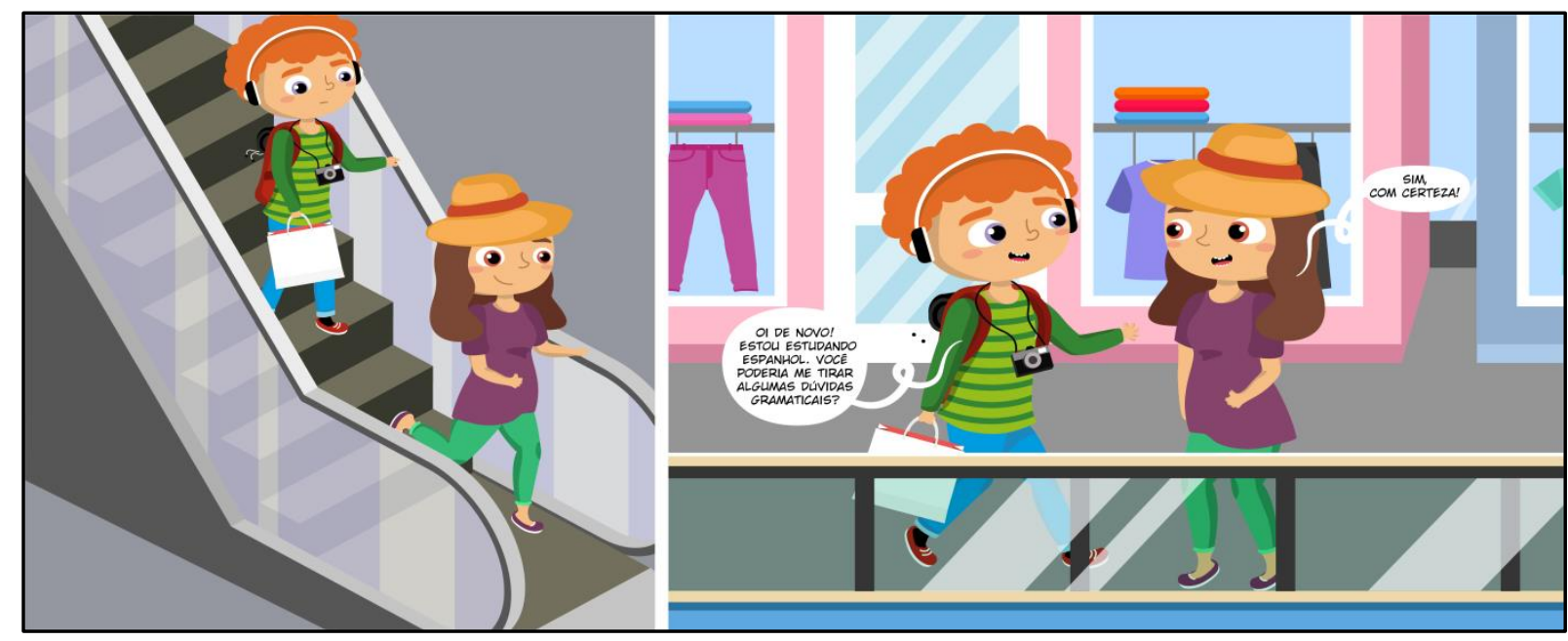

Fonte: Autoral. Elaborado pela equipe de desenvolvimento.

Progressão: o curso se desenvolverá no contexto de um jogo de trilha (Figura 9). Cada casa da trilha corresponde a um assunto do curso (casas na cor azul). Para passar de um conteúdo para outro, exemplificando, o aluno inicia o curso vendo o assunto do Módulo 1 /unidad 1: ihola! ¿cómo te va? / Contenidos funcionales, que estão indicados pelas casas azuis; após ver todo o assunto desse "contenido", ele realiza uma atividade de avaliação, indicado pelas casas na cor verde, para que possa avançar para os assuntos do Módulo 1 /unidad 1: ihola! ¿cómo te va? / Contenidos lexicales, e assim sucessivamente. Os desafios (casas na cor verde) podem ser um quiz com perguntas, por exemplo. As casas na cor rosa correspondem a conteúdos complementares de aprofundamento. Analisando os conteúdos didáticos do curso, percebeu-se que os "Contenidos culturales" e a "síntesis contrastiva" poderiam se enquadrar nessa proposta. Os conteúdos não seriam obrigatórios; caso o aluno opte em passar por essas casas, ganhará troféus e pontuações. 
Figura 9 - Trilha do curso

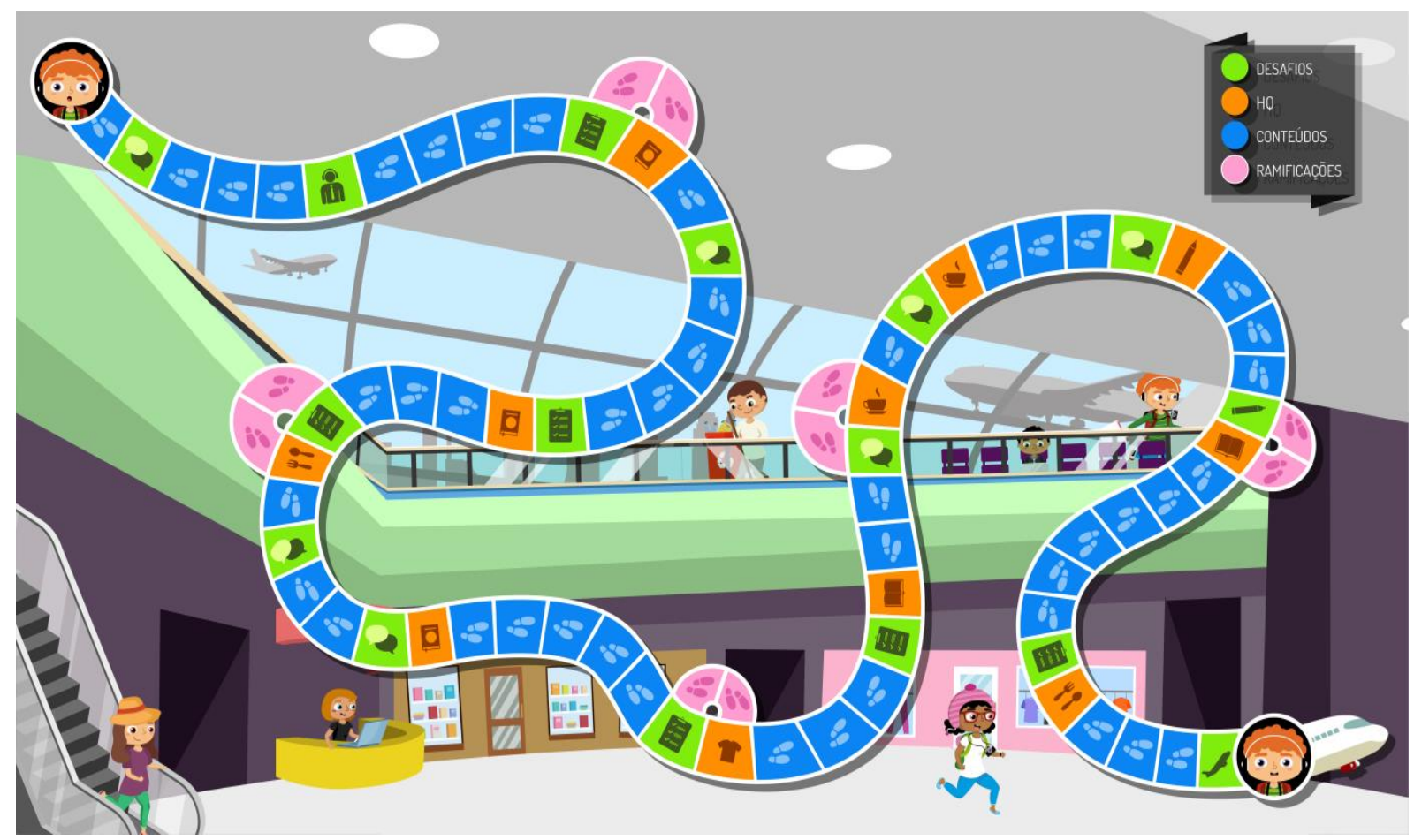

Fonte: Autoral. Elaborado pela equipe de desenvolvimento.

Restrições: os avanços no curso ocorrerão de forma sequencial e em determinados pontos existirá pré-requisitos (desafios) para dar continuidade ao curso.

Emoções: a intenção é despertar a curiosidade do aluno, para que ele queira avançar nas casas da trilha e saber o que vai ocorrer com o personagem ao longo da história e estimular o sentimento de desafio para que consiga chegar ao final do percurso (curso). A possibilidade de saber como outros colegas estão se desenvolvendo no curso também poderá provocar estímulos ao participante.

\section{Mecânica}

Desafios: em diversos momentos do curso, aparecerão perguntas sobre o conteúdo visto, no formato de um questionário (casas em verde, Figura 9).

Feedback: a própria trilha servirá para dar ao aluno o feedback sobre o seu desenvolvimento no curso, de acordo com o seu posicionamento na mesma, pois visualizara quanto do conteúdo do curso já estudou e quanto falta para concluir. Também nos desafios (questionários) haverá retorno das respostas dadas pelos alunos, ao fim dos questionários, através de respostas automáticas do ambiente, inseridas pelo professor conteudista orientando sobre o assunto nas repostas erradas, além de incentivar o aluno a continuar estudando e complementando conteúdos nas repostas corretas. 
Recompensas: ao passar pelas casas na cor rosa (Figura 9), nos conteúdos complementares e/ou aprofundamento, o participante ganhará troféus e pontuações. As recompensas devem ser recebidas a cada conquista ou ação importante do jogador. Então, o aluno é recompensado pelo seu sucesso e não punido por seus fracassos. Ao utilizar as técnicas de jogos, os alunos aprendem cometendo erros, sendo motivados a tentar de novo e a superar seu fracasso, isto é, ocorre uma ressignificação (SHELDON, 2012).

Estados de vitória: será vencedor o aluno que chegar ao final da trilha, vendo todo o conteúdo do curso e passando por seus desafios.

\section{Componentes}

Personagem: foram criados dois personagens para o curso, um do sexo masculino e outro do sexo feminino.

Pontos: com os avanços nas casas, o aluno acumulará pontos de experiência no curso. Cada vez que avança uma casa o aluno ganha 100 pontos. Há outras formas de ganhar pontos também como nos desafios e passando pelos conteúdos complementares.

Medalhas: o aluno receberá medalhas (Figura 10) quando passar por um desafio sem errar nenhuma pergunta, equivalente aos troféus que o aluno recebe quando passar pelas casas (cor rosa) com os conteúdos complementares.

Rankings: com as pontuações e medalhas acumuladas, será elaborado um ranqueamento com os alunos mais eficientes (Figura 10).

Os elementos de pontuação, medalhas, ranqueamento e personagem, interligados entre si e visíveis ao longo do curso (Figura 10 ), mostraram-se úteis aos objetivos traçados. $\mathrm{Na}$ preparação do design da gamificação, teve-se a preocupação em não supervalorizar esses elementos e em alinha-los à proposta do curso, com regras claras. Contudo, apesar dos benefícios apontados, alguns questionamentos têm sido levantados, como a prática constante de recompensas. Premiações sem planejamento podem ocasionar modelos condicionados nos quais as pessoas só participam para serem premiadas. Além disso, pode gerar competitividade excessiva e possíveis conflitos entre jogadores.

Uma das principais questões evidenciadas na pesquisa foi o uso de pontos, medalhas e ranqueamento, $\mathrm{PBL}$ (points, badges, leaderboard). Muitos autores alertam para problemas relacionados ao uso de $\mathrm{PBL}$, embora os questionamentos estejam relacionados ao uso exclusivo dessas estratégias em gamificações e não na utilização dos mesmos. Constatamos, através relatos dos alunos e das observações no ambiente do curso, que o PBL ajudou na motivação e engajamento dos participantes. O estímulo à interação dos estudantes com o conteúdo e com os seus colegas é desejável em um ambiente de aprendizagem participativo, autônomo e colaborativo, onde o conhecimento perpassa a essas conexões estimuladas e 
estabelecidas. Com o uso adequado dos elementos da gamificação, como desafios, regras claras e específicas, interatividade, fornecimento de feedback, quantificação de resultados, entre outras estratégias, comprovamos que podemos ter cursos $\mathrm{MOOC}$ atrativos e que favorecem ao aprendizado, baseando-se em técnicas de engajamento e estratégias motivacionais e colaborativas.

Desbloqueio de conteúdo: desbloqueio que ocorre após o jogador cumprir determinados objetivos.

Figura 10 - Visão de alguns elementos da gamificação no curso

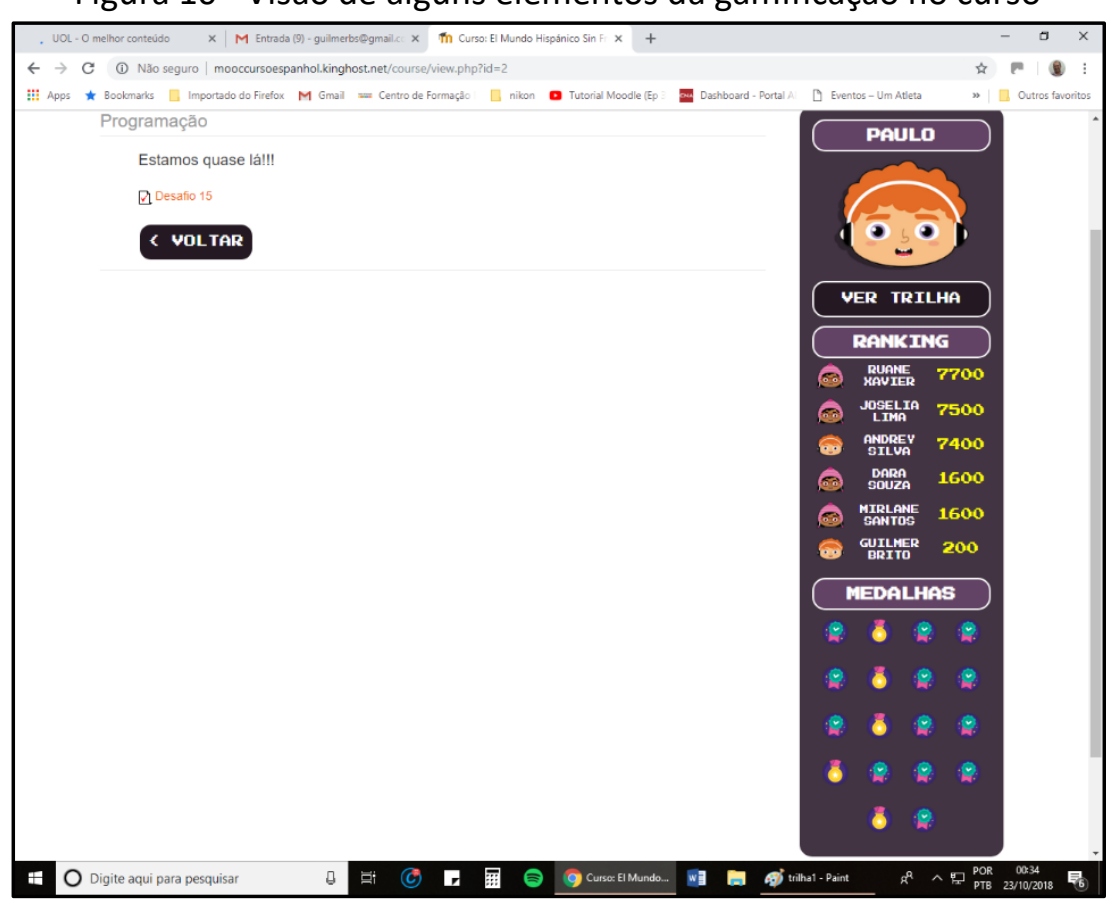

Fonte: Autoral. Elaborado pela equipe de desenvolvimento.

Outros elementos de gamificação poderiam ter sido incorporados ao curso, principalmente os componentes, mas levaram-se em consideração o tempo e o grau de dificuldade para a implementação do elemento, que impactaria no cronograma definido para a conclusão da pesquisa.

A partir da experiência de construção do SPOC Gamificado: El Mundo Hispánico Sin Fronteras, foi realizada a oferta do curso para validar as estratégias utilizadas e verificar a percepção dos participantes sobre o curso.

\section{Oferta e validação do curso}

Após a criação do curso de espanhol na proposta de um SPOC gamificado, foi realizada a oferta do curso para validar as estratégias utilizadas. Para atender às características de 
cursos SPOC, o critério estabelecido para participação do curso-piloto seria o interesse na língua espanhola, mas, por se tratar de um curso experimental, se fez necessário ter controle sobre os inscritos. Em outras palavras, as inscrições não foram abertas (livres), mas foram realizadas de forma manual pelo pesquisador, após ser esclarecidos para os voluntários os objetivos da pesquisa e de terem sido assinados os termos de consentimento livre e esclarecido (TCLE), contido no protocolo aprovado pelo comitê de ética e pesquisa.

Seguindo o critério de interesse em língua espanhola, foi cadastrado um primeiro grupo no curso, com alunos da turma do sexto período da disciplina Língua Espanhola IV, do Curso de Letras da Ufal. Nessa turma havia 9 (nove) alunos matriculados, em que todos sinalizaram interesse em participar do curso. Após as inscrições dos participantes no curso, e para reproduzir de maneira fidedigna a forma que se desenvolve cursos MOOCs, não foi mantido nenhum contato do pesquisador com os alunos ao longo do curso, objetivando não exercer nenhum papel de tutor ou algo nesse sentido, que descaracterizaria o modelo de curso MOOC adotado na pesquisa.

Só ao final do período estabelecido para o curso, foi realizado contato com todos a fim de obter informações sobre a participação do aluno no AVA do curso.

Paralelo a essa oferta, foi também realizado o convite a alguns professores de língua espanhola para que participassem do curso. Três professores demonstraram interesse e foram matriculados no curso. Foram adotados os mesmos procedimentos já descritos com os alunos do primeiro grupo.

Por fim, foi cadastrado um terceiro grupo de alunos no curso, formado por pessoas que já tinham realizado ou estão fazendo curso básico de língua espanhola, em alguma instituição de língua estrangeira. Nesse grupo foram inscritos 19 alunos. Ao total foram inscritos 31 participantes no curso. Desse total uma (1) professora do segundo grupo e dez (10) pessoas do terceiro grupo não entraram no ambiente do curso nenhuma vez, sendo então desconsiderados na análise dos dados da pesquisa. Então foram totalizados 20 alunos ativos, sendo 9 do primeiro grupo, 2 do segundo e 9 do terceiro.

Após determinado período, também foram enviados e-mails com as perguntas de avaliação para os participantes que não completaram o curso e que no mínimo tivessem acessado o ambiente pelo menos uma vez. Para manter o anonimato dos alunos voluntários, foi adotada uma codificação para identificar os alunos; eles serão identificados pela nomenclatura Aluno 1, Aluno 2, (...), seguindo a ordem de inscrição na plataforma. Além das perguntas respondidas pelos alunos, foi objeto de avaliação o percurso do aluno ao longo do curso. Nesse sentido, os relatórios (logs) do AVA Moodle também contribuíram para essa análise.

Em relação ao nível de contentamento com a proposta do curso, 85\% aprovaram o curso e o indicariam para outras pessoas (amigos, alunos, familiares, etc.), como relatou a Aluna 1: "De um modo geral eu gostei muito, o curso foi muito bom e divertido, e acredito 
com alguns ajustes e modificações poderá ficar ainda melhor e alcançar a excelência". O Aluno 5 afirmou: "Achei superinteressante encarar o ensino de uma língua estrangeira, no caso o espanhol, na forma de um jogo. É, no meu ponto de vista, uma forma de romper com o ensino tradicional da sala de aula e até de um ensino a distância, que ainda assim, em sua grande maioria, está baseada em uma visão tradicional, para ser aprendida através de um jogo com desafios, $\mathrm{HQ}$ e, principalmente um enredo. E o curso está bem caracterizado como um jogo, visto que há a superação das casas, através dos conteúdos, desafios e a pontuação, além das medalhas para reconhecimento do avanço e da internalização do conhecimento".

O índice de satisfação com o curso parece ter influenciado na alta taxa, para um MOOC, de conclusão alcançada: $55 \%$ dos alunos concluíram totalmente a trilha, chegando ao final do curso. Segundo Aluno 8, "Na minha opinião a forma de uma trilha (jogo) é bastante instigante, e faz com que a pessoa almeje chegar ao final da trilha, e para isso passando por cada etapa e aprendendo os conteúdos".

As declarações dos alunos confirmam a relevância do fator motivacional ao acompanhar o conteúdo de uma narrativa no curso gamificado. Com isso, demonstramos o estímulo ao interesse no aluno a continuar avançando no curso para acompanhar os próximos passos da estória ou acompanhar um amigo ou conhecido, de certa forma, impactando em sua motivação intrínseca. Também identificamos que a premiação que era dada aos alunos quando avançavam na trilha foi um fator importante no interesse deles. Percebe-se com isso que, por ter que cumprir e realizar ações, os alunos se motivavam pelo seu próprio desenvolvimento ao ver acontecer e funcionar o constructo de suas práticas.

Os pontos criticados foram o tempo de duração de alguns vídeos, acharam longos demais, bem como o formato dos desafios. Os vídeos do curso em sua maioria tinham entre 2 a 3 minutos, mas havia 3 vídeos maiores com 4, 6 e 11 minutos. A Aluna 15 disse: "Os desafios me pareceram muito chatos, como se fosse uma prova só que com o nome desafio". O Aluno 5 pontuou no mesmo sentido: "Como ponto negativo, apenas levanto o problema com a formulação de algumas questões dos desafios". Também nesse sentido o Aluno 9 afirmou: "Um outro ponto negativo foi os desafios, serem bem parecidos com uma prova escolar".

O formato de trilha, o enredo e os personagens formam os elementos mais elogiados, como podemos sintetizar no relato do Aluno 3: "Os pontos positivos são: a forma divertida do curso, em forma de trilha, e dessa forma incentivando ao aluno aprender de forma divertida, e o enredo também, toda a história do personagem". O Aluno 10 afirmou que: "Como ponto positivo ressalto, novamente, toda a construção do jogo, desde a sua forma de criação, os desafios, história, HQs, etc. É um ensino/jogo que rompe com paradigmas de ensino e é, também, um modelo para se pensar em novas formas de trabalhar a Língua estrangeira".

Essas duas respostas evidenciaram o entusiasmo e a importância da contextualização para auxiliar no desenvolvimento do curso gamificado, ao mesmo tempo que explicita que era 
um desafio acompanhar a história e avançar na trilha. Portanto, conforme mostrado, foi possível perceber um maior engajamento dos alunos, por terem um propósito a seguir em seu aprendizado.

Um dos elementos que colaborou para o engajamento no curso pode ser identificado no relato do Aluno 8: "Avalio positivamente todas as estratégias utilizadas no jogo para o avanço, internalização e desenvolvimento do conhecimento por parte dos alunos. Além disso, estas estratégias são vitais para caracterizar o curso como um jogo divertido. Ressalto a presença da pontuação de todos os jogadores, isso nos instiga a dar o melhor para passar os coleguinhas e estar no topo do nível".

A resposta do aluno 8 enfatiza que o uso do ranking o fez querer participar e ganhar cada vez mais pontos para ficar entre os primeiros colocados. Conforme os alunos, o funcionamento com um ranking e pontuação fez com que eles testassem seus conhecimentos, de fato. Portanto, as respostas dos alunos demonstram que eles se motivavam e sentiam-se engajados com o uso de pontos e ranking online.

O foco do curso não estava na acumulação de pontos e medalhas. O status de "vitória" não estava em ser o primeiro do ranking. O objetiva era concluir a trilha, ultrapassar os desafios, então os elementos do PBL entraram de forma complementar, servia para mensurar o seu desenvolvimento em relação aos seus colegas, sem que isso impactasse em nada no seu status de "vitória". Também serviu para que o aluno identificasse se visualizou todo o conteúdo do curso, pois só conseguiria todas as medalhas se percorresse todas as casas da trilha, incluindo as de conteúdos complementares (não-obrigatórios). Nesse contexto, o PBL se mostrou útil e benéfico, para a proposta do curso e foi sinalizado como elemento positivo pelos participantes.

Salientamos que se faz necessário análises mais profundas para avaliar os elementos positivos e negativos nesse desenvolvimento e conclusão mais rápido no curso, mas em um modelo de curso MOOC autoinstrucional e motivacional, o próprio participante tem o poder de definir e determinar os seus objetivos.

Constatamos, nos relatos dos alunos e no acompanhamento das interações no ambiente, o potencial do MOOC gamificado para elevar ou manter os níveis de engajamento, por meio do estímulo à motivação intrínseca do sujeito, utilizando cenários lúdicos para simulação e exploração, com objetivos extrínsecos, apoiados em elementos utilizados em jogos. O Aluno 16 destacou que: "As estratégias utilizadas foram bem legais; ter todo um contexto envolvendo um personagem; as medalhas, as recompensas".

\section{Considerações finais}

Nesta pesquisa apresentamos o uso da gamificação aplicada a MOOC. A proposta 
apresentada não teve por objetivo mudar a concepção pedagógica que um curso MOOC pode assumir, mas visou, como Kapp (2012) destaca, promover um nível de interesse e uma nova maneira de agrupar um conjunto de elementos psicológicos em um ambiente promotor de engajamento e motivação. Ainda segundo Hanus e Fox (2015), em um contexto educacional, a gamificação pode ser utilizada de várias formas para incentivar os alunos. Isso favorece que os alunos possam apreender e realizar tarefas, antes tediosas, de uma forma nova e motivada.

Através do curso desenvolvido foi possível constatar alguns elementos que contribuem para a construção de cursos MOOCs utilizando a gamificação, que foi o problema norteador desta pesquisa. A estrutura de uma trilha, as $\mathrm{HQ}$, os personagens e o ranking, se mostraram como sendo elementos importantes para o design pedagógico de cursos $\mathrm{MOOC}$, favorecendo na motivação e no engajamento dos participantes os depoimentos dos alunos e o índice de conclusão do curso confirmam essa constatação. Também ficou constatado que devesse ficar atento na construção de $\mathrm{MOOC}$ gamificados na elaboração de atividades diversificadas e na possibilidade de personalização do ambiente, como por exemplo, a caracterização de avatares e possibilidade de criar grupos para ranking separados. Os elementos de personalização se mostraram como sendo importantes para os participantes.

Concluímos que o uso de MOOCs gamificados podem motivar o aluno no ambiente do curso e promover uma maior interação do aluno com os materiais didáticos e atividades. Para obter seus potenciais benefícios, porém, é necessário planejar os objetivos educacionais, discutir as estratégias a serem utilizadas para aplicação dos conceitos e mecânicas dos jogos, além de analisar experiências já promovidas, como a realizada nesta pesquisa. Por fim, com o estudo foi possível confirmar a riqueza de possibilidades de um ambiente virtual de aprendizagem aberto, online e gratuito, onde é concebível criar, compartilhar e aprender.

\section{Referências}

BACICH, L.; MORAN, J. (Org.). Metodologias ativas para uma educação inovadora: uma abordagem teórico-prática. Porto Alegre, Brasil: Penso, 2018.

BACICH, L.; TANZI NETO, A.; TREVISANI, F. de Mello. (Org.). Ensino híbrido: personalização e tecnologia na educação. Porto Alegre, Brasil: Penso, 2015.

BATES, A. W. Educar na era digital: design, ensino e aprendizagem. São Paulo: Artesanato Educacional, 2016.

BERGMANN, J.; SAMS, A. Sala de aula invertida: uma metodologia ativa de aprendizagem. Rio de Janeiro, Brasil: LTC, 2016.

DETERDING, S.; DIXON, D.; KHALED, R.; NACKE, L. From game design elements to gamefulness: defining "gamification". 2011.2 Disponível https://www.cs.auckland.ac.nz/courses/compsci747s2c/lectures/paul/definitiondeterding.pdf. Acesso em: 21 maio, 2017. https://doi.org/10.1145/2181037.2181040 FADEL, L. M.; ULBRICHT, V. R.; BATISTA, C. R.; E VANZIN, T. (org.). Gamificação na educação. 
São Paulo: Pimenta Cultural. 2014.

GROVER, S; FRANZ, P.; SCHNEIDER, E.; PEA, R. The MOOC as distributed intelligence: dimensions of a framework \& evaluation of MOOCs. 2013.

HANUS, M. D.; FOX, J. Assessing the effects of gamification in the classroom: a longitudinal study on intrinsic motivation, social comparison, satisfaction, effort, and academic performance. Computers \& Education, v. 80, p. 152-161, 2015. https://doi.org/10.1016/j.compedu.2014.08.019

HORN, M.; STAKER, H. Blended: usando a inovação disruptiva para aprimorar a educação. Porto Alegre, Brasil: Penso, 2015.

KAPP, K. M. The gamification of learning and instruction: game-based methods and strategies for training and education. San Francisco: Pfeiffer, 2012. E-books. Disponível em: https://www.amazon.com.br/Gamification-Learning-Instruction-Game-Based-

Strategies/dp/1118096347. https://doi.org/10.1145/2207270.2211316

KAPP, K. M.; BLAIR, L.; MESCH, R. The gamification of learning and instruction fieldbook: ideas into practice. EUA: Wiley. 2014.

LIN, L. MOOCS and SPOCs: Evolution and Inheritance of Online Education. 2016. Disponível em: https://www.atlantis-press.com/proceedings/emcs-16/25848565. Acesso em: 8 abr. 2019.

MATTA, C. E.; FIGUEIREDO, A. P. S. MOOC: transformação das práticas de aprendizagem. In: CONGRESSO BRASILEIRO DE ENSINO SUPERIOR A DISTÂNCIA, 10., 2013, Belém. Anais... Belém: UNIREDE, 2013.

MATTAR, J. Games em educação: como os natives digitais aprendem. São Paulo: Pearson, 2010.

MATTAR, J. Os MOOC já eram... o negócio agora são os SPOCs! 2013. Disponível em: http://joaomattar.com/blog/2013/11/03/os-moocs-ja-eram-o-negocio-agora-sao-os-spocs/. Acesso em: 3 mar. 2019.

MCGONIGAL, J. Reality is broken: why games make us better and how they can change the world. 2011. 396 p. E-book. ISBN 9780143120612.

MÉNDEZ GARCÍA, C. M. Diseño e implementación de cursos abiertos masivos en línea (MOOC): expectativas y consideraciones prácticas. Revista de Educación a Distancia, n. 39, dez. 2013. Disponível em: http://www.um.es/EAD/red/39/mendez. pdf. Acesso em: 27 jan. 2017.

MUNTEAN, C. I. Raising engagement in e-learning through gamification. In: THE INTERNATIONAL CONFERENCE ON VIRTUAL LEARNING, ${ }^{\text {th }}$, 2011. Proceedings... Disponível em: http://icvl.eu/2011/disc/icvl/documente/pdf/met/ICVL_ Models And Methodologies_ paper42.pdf. Acesso em: 17 set. 2017.

PERNA, L. W.; RUBY, A. Life cycle of a million MOOC users, 2013. Disponível em: http://www.gse.upenn.edu/pdf/ahEAD/perna_ruby_boruch_moocs_dec2013.pdf. Acesso em: 19 jan. 2017.

PIMENTEL, F. S. C. Conceituando gamificação na educação. Disponível em: http://fernandoscpimentel.blogspot.com/2018/01/conceituando-gamificacao-na- 
educacao.html. Acesso em: 16 abr. 2018.

SCHLEMMER, E. Gamificação em espaços de convivência híbridos e multimodais: design e cognição em discussão. Revista da FAEEBA: Educação e Contemporaneidade, Salvador, v. 23, n. 42, p. 73-89, jul./dez. 2014. https://doi.org/10.21879/faeeba2358-0194.v23.n42.1029

SCHMITZ, B.; KLEMKE, R., SPECHT, M. Effects of mobile gaming patterns on learning outcomes: a literature review. International Journal of Technology Enhanced Learning, v. 4, n. 5/6, p. 345358.

SELINGO, J. J. Demystifying the MOOC. The New York Times, New York, Oct. 2014. Section Notebook/Online Education. Disponível em: https://www.nytimes. com/2014/11/02/education/edlife/demystifying-the-mooc.html. Acesso em: 21 maio, 2018.

SHELDON, L. The multiplayer classroom: designing coursework as a game. Boston: Cengage Learning, 2012.

STOTT, A.; NEUSTADTER, C. Analysis of gamification in education. 2013. Disponível em: http://clab.iat.sfu.ca/pubs/Stott-Gamification.pdf. Acesso em: 17 mar. 2017.

TALBERT, R. Guia para utilização da aprendizagem invertida no ensino superior. Porto Alegre: Brasil: Penso, 2019.

VALENTE, J. A. Blended learning e as mudanças no ensino superior: a proposta da sala de aula invertida. Educar em Revista, Curitiba, Brasil, Edição Especial n. 4, p. 79-97. Editora UFPR, 2014. https://doi.org/10.1590/0104-4060.38645

VIANNA, Y.; VIANNA M.; MEDINA, B.; TANAKA, S. (org.). Gamification, Inc.: como reinventar empresas a partir de jogos. Rio de Janeiro: MJV, 2013.

WERBACH, K.; HUNTER, D. For the win: how game thinking can revolutionize your business. Filadélfia: Wharton Digital Press, 2012.

YUAN, L., POWELL, S., E CETIS, J. MOOCs and open education: implications for higher education. Cetis White Paper, 2013.

ZICHERMANN, G.; CUNNINGHAM, C. Gamification by design: implementing game mechanics in web and mobile apps. Sebastopol: O'Reilly Media Inc, 2011.

Recebido em: 07/06/2019

Aceito em: 20/11/2019 